\title{
Algae: Advanced Biofuels and Other Opportunities
}

\author{
Lauro A. Ribeiro, Patrícia Dias, Luis Felipe Nascimento \\ and Patrícia Pereira da Silva
}

\begin{abstract}
Despite the challenges, depending on the local conditions and practices, renewable energy sources are already a significant contribution to the energy mix. Although this is true for electricity generation, the same does not apply for the transportation sector, where the available renewable sources are limited and still have a modest impact in the overall consumption. In this context, advanced biofuels such as microalgae are worldwide believed to be a better choice for achieving the goals of incorporating non-food-based biofuels into the biofuel market and overcoming landuse issues. Compared to other biofuel technologies, the most favorable factors for the cultivation of microalgae for the production of biofuels are they can be grown in brackish water and on non-fertile land, and the oil yield production is far superior. Main challenges are currently the feasibility of large-scale commercialization, since the majority of economic and financial analyses rely on pilot-scale projects. Environmental issues are most likely to diverge opinions from experts. This chapter presents a review of microalgae cultivation (species, usage, processes, and culture) and biofuel production, highlighting advantages and challenges of algae biofuel.
\end{abstract}

\footnotetext{
L. A. Ribeiro $(\triangle)$

School of Sciences and Technology, University of Coimbra and INESCC, R. Antero de Quental, 199, 3030-030 Coimbra, Portugal

e-mail: 1ribeiro@inescc.pt

P. Dias · L. F. Nascimento Management School, Federal University of Rio Grande do Sul, Av. Washington Luiz, 855, 90010-460 Porto Alegre, Brazil e-mail: patricia.dias@ufrgs.br

L. F. Nascimento

e-mail: nascimentolf@gmail.com

P. P. da Silva

School of Economics, University of Coimbra and INESCC, R. Antero de Quental, 199, 3030-030 Coimbra, Portugal

e-mail: patsilva@fe.uc.pt
} 


\section{Introduction}

Innovative technologies and sources of energy must be developed to replace fossil fuels and contribute to the reductions of emissions of greenhouse gases associated with their use. Biofuels are particularly important as an option by means of transportation that lack of other fuel options (especially trucks, ships, and aircrafts). However, alternative sources of biofuel derived from terrestrial crops such as sugarcane, soybeans, maize, and rapeseed impose pressure on food markets, contribute to water scarcity, and precipitate forest devastation. In this way, the sustainability of biofuels will depend on the development of viable, sustainable, advanced technologies that do not appear to be yet commercially viable.

In this perspective, algal biofuels are generating substantial awareness in many countries. In the United States, they may contribute to achieve the biofuel production targets set by the Energy Independence and Security Act of 2007. Likewise, in the European Union (EU), they may assist to the achievement of goals established in the recent Renewables Directive. In order to address the technical-economic barriers to the further development of this type of bioenergy, it is thus necessary to contribute with a study that incorporates biomass feedstock availability assessment, production, management, and harvesting in support of the upscaling of this promising technology.

Biodiesel and bioethanol are the two liquid biofuel options currently looked upon with more attention and under more vigorous development, since they can be used in today automobiles with little or no modifications of engines, for replacing diesel and gasoline, respectively. The Directive 2009/28/CE also targets the transportation sector fuels; in particular, each member state should reach a minimum $10 \%$ share of renewable energy by 2020 . Complementary, the Directive also states that this must be possible by using electricity and sustainable biofuels (i.e., based on a sustainable production). It also mentions that correct sustainability criteria should be adopted for biofuels, so that the rising world demand for biofuels does not destroy or damage land biodiversity and establish many others' recommendations to ensure total sustainability of biofuels. An interesting point of this Directive is that, it recommends member states to incentive and support the use of biofuels that add supplementary diversifying benefits, such second- and third-generation biofuels (e.g., biodiesel from microalgae or bioethanol from lignocellulosic materials). Some changes were recently proposed to the Directive 2009/28/CE (EC 2012), in particular dealing with the calculation of the carbon footprint, namely how to account for the ILUC (indirect land-use changes), and setting new goals deemed more adequate to promote the growing European biofuels industry.

In this context, the overall purpose of this literature review is to provide an integrated assessment of the potential of microalgae as a source to produce biofuels, while confronting it with competing emerging biofuel technologies. It is intended to provide a comprehensive state of the art technology summary for producing fuels and coproducts from algal feedstocks and to draw some insights into the feasibility and techno-economic challenges associated with scaling up of processes. 


\section{Algae Cultivation Techniques}

The microalgae are photosynthetic organisms can grow in a wide variety of environments and conditions, including freshwater, salty, and brackish water (Benemann 2012). Their mechanism of photosynthesis is similar to higher plants, with the difference that the conversion of solar energy is generally more efficient because of their simplified cellular structure and more efficient access to water, $\mathrm{CO}_{2}$, and other nutrients.

Its uniqueness that separates them from other microorganisms is due to presence of chlorophyll and having photosynthetic ability in a single algal cell, therefore allowing easy operation for biomass generation and effective genetic and metabolic research in a much shorter time period than conventional plants (Singh and Sharma 2012).

In addition, the cultivation requirements are quite small, as most species only need water, $\mathrm{CO}_{2}$, and some essential nutrients such as nitrates, phosphates, and potassium, without needing the use of pesticides or fertilizers (Groom et al. 2008; Singh and Sharma 2012). Microalgae can produce lipids, proteins, and carbohydrates in large amounts over short periods of time. For these reasons, microalgae are capable of producing 30 times as much oil per unit of land area compared to terrestrial oilseed (Sheehan et al. 1998). And these oil can be processed into both biofuels and valuable coproducts (Singh and Sharma 2012).

The microalgae cultivation can be heterotrophic or autotrophic. The heterotrophic method is a biochemical conversion that relies on input feedstock derived from an upstream photosynthetic source. This approach uses closed bioreactor systems in a biochemical conversion process without light inputs. This dark fermentation process is based on the consumption of simple organic carbon compounds, such as sugars or acetate. The cultivation of algae using cellulosic sugars produced from wood and agricultural wastes or purpose-grown energy crops is an area of active research and development (Buford et al. 2012).

In the other hand, the autotrophic cultivation requires only inorganic compounds such as $\mathrm{CO}_{2}$, salts, and a source of light energy for their growth. This photosynthetic conversion involves two main methods: open ponds and closed photobioreactors (PBRs). The biomass produced in these autotrophic processes includes lipids that can be converted to fuels (Brennan and Owende 2010; Buford et al. 2012).

According to Benemann (2012), algae have been essentially produced in open ponds with the main strains currently being cultivated are Spirulina, Chlorella, Dunaliella, and Haematococcus. Most designs include mixing systems that use paddle wheels and carbonation techniques to supply and transfer $\mathrm{CO}_{2}$ (in-ground carbonation pit, bubble covers, and in-pound sumps ${ }^{1}$ ).

Microalgae are also grown in tanks and small-scale PBRs, in hundreds of different systems around the world, producing from small amounts to huge sums of

${ }^{1}$ http://www.powerplantccs.com/ccs/cap/fut/alg/alg_carbonation.html. 
biomass annually. In this closed autotrophic approach, algae grow with sunlight or artificial lighting (Benemann 2012; Buford et al. 2012). Different types of PBRs have been designed and developed for cultivating algae that can be horizontal, vertical, tubular, flat, etc. (Benemann 2012; Singh and Sharma 2012). Each of these PBRs has their own advantages and disadvantages. Several studies are being developed which may overcome their limitations in the years to come (Singh and Sharma 2012).

\subsection{Comparing Open Ponds and Photobioreactors Systems}

Commercial algae production facilities employ both open and closed cultivation systems. Each of these has advantages and disadvantages, but both require high capital input (Pienkos and Darzins 2009). Open ponds are much more cheaper than closed systems because it demands relatively high capital and O\&M costs associated with installation and operation of PBRs (Benemann 2012; Buford et al. 2012).

Lower costs and the possibility to scale up to several hectares make open ponds the main choice for algae commercial production (Benemann 2012). However, open pond cultures suffer from many limitations that can disrupt algal productivity during unexpected environmental events. Another challenge for this system includes having access to an adequate supply of water for growth due to continuing loss of water through evaporation. Therefore, open ponds must be in a geographic setting that has a fairly near source of water and a relatively flat terrain to avoid costly earthworks (Buford et al. 2012). Moreover, the open systems are susceptible to wind-born biological agents that can affect the cultivation, such as grazers, infectious fungi, lytic bacteria, viruses, other algae, and also lower temperatures in colder climates (Benemann 2012).

These open pond limitations stimulate PBRs development; however, only a few commercial plants use closed PBRs systems, mainly due to high costs as mentioned before. Nowadays, according to Benemann (2012), microalgae cannot be grown in PBRs for commodities and are not even successful for high-value products. However, PBRs can be used for seed culture production, though only for $\sim 0.1 \%$ of the biomass. Closed PBRs are significantly more expensive to construct, but have not been engineered to the extent of other reactors in commercial practice, and so there may be opportunities for significant cost reductions.

Neither open ponds nor closed PBRs are mature technologies. Therefore, until large-scale systems are built and operated over a number of years, many uncertainties will remain. Cultivation issues for both open and closed systems, such as reactor construction materials, mixing, optimal cultivation scale, heating/cooling, evaporation, $\mathrm{O}_{2}$ build-up, and $\mathrm{CO}_{2}$ administration, have been considered and explored to some degree, but more definitive answers await detailed and expansive scale-up evaluations (Pienkos and Darzins 2009). 
Concerning the various algal species and strains, they vary from study to study, depending on location and culture techniques. For that reason, it is not yet possible to predict what species or strain will be the best suited for commercial biofuel production, but it is most likely that it will differ from case to case, depending on the location, cultivation techniques chosen, processing technologies available, nutrients source, local climacteric conditions, and among other potential factors.

\subsection{Harvesting Methods}

The algal biomass production process requires one or more solid-liquid separation steps. Generally, first stage involves a separation of biomass from the bulk suspension (including flocculation, flotation, or gravity sedimentation). The second stage (thickening) raises the concentration of the slurry through techniques such as centrifugation, filtration, and ultrasonic aggregation; hence, it is generally a more energy intensive step than bulk harvesting (Brennan and Owende 2010).

The flocculation is the first (preparatory) stage that is intended to aggregate the microalgae cells in order to increase the effective "particle" size. Unlike flocculation, flotation methods are based on the trapping of algae cells, using dispersed microair bubbles. Gravity and centrifugation sedimentation methods are based on characteristics of suspended solids and are determined by density and radius of algae cells and sedimentation velocity. It is the most common harvesting technique for algae biomass in wastewater treatment because of the large volumes treated and the low value of the biomass generated. The filtration process is better suited for harvesting relatively large $(>70 \mathrm{~mm})$ microalgae such as Coelastrum and Spirulina. The membrane microfiltration and ultrafiltration (hydrostatic pressure) are viable alternatives to recovery of biomass from smaller algae cells $(<30 \mathrm{~mm})$, such as Dunaliella and Chlorella (Brennan and Owende 2010). Some species are much easier to harvest, considering algae densities and size. The strain characteristics, cost, and energy efficiency are the main factors to select harvesting technology (Brennan and Owende 2010).

\subsection{Extraction of Algae Oil}

The common techniques for oil extraction are mechanical pressing, the usage solvents, and supercritical fluid extraction. Each of these different methods presents its own advantages and disadvantages. The first oil extraction method can be divided into expression and ultrasonic-assisted extraction and the efficiency normally ranges from 70 to $75 \%$ (Rengel 2008). The main drawback of this method is that it generally requires drying the algae beforehand, which is an energy intensive step. 
Using solvents such as n-hexane, benzene, ethanol, chloroform, and diethyl ether can efficiently extract the fatty acids from algae cells. However, the use of chemicals in the process could present environmental, safety, and health issues. In many cases, manufacturers of algae oil use a combination of mechanical pressing and chemical solvents in extracting oil to improve efficiency (around $95 \%$ ).

Supercritical extraction requires high-pressure equipment that is both expensive and energy intensive. In this process, carbon dioxide is heated and compressed until it reaches a liquid-gas state. Then, it is applied to the harvested algae and acts like a solvent (Mendes et al. 1995; Ferreira et al. 2013).

Apart from these, there are some other more expensive and less known and utilized methods which are enzymatic extraction that uses enzymes to degrade the cell walls with water acting as the solvent; and osmotic shock is a sudden reduction in osmotic pressure that can cause cells in a solution to rupture.

Once the oil is extracted through these methods, it is referred to as "green crude." However, it is not ready to be used as biofuel until it undergoes a process called transesterification. This step is a chemical reaction in which triglycerides of the oil react with methanol or ethanol to produce (m)ethyl esters and glycerol (Rengel 2008). This reaction creates a mix of biodiesel and glycerol that is further processed to be separated and leaves ready to use biodiesel.

Direct conversions from a non-dry state are being studied and some possibilities that may play an important role in offsetting the costs and improve oil extraction efficiency are arising. Among these, it is important to highlight in situ transesterification and hydrothermal liquefaction (Chen et al. 2009; Patil et al. 2008) Nevertheless, due to limited-level information in these processes for algae, more research in these areas is still needed.

Meanwhile, a lot of work is being made to reduce energy input and costs of extraction processes. Many industries claim they have come up with cost-effective methods in this area; however, until large-scale facilities are deployed, it is hard to tell which one will work in a large-scale basis.

The whole algae, bio oil, or the residues from oil extraction are excellent feedstock for making other fuels and products via different processes. Some of these products will be presented in the next chapter.

\subsection{Algae: Products and Processes}

Microalgae have been studied for many years for production of commodities and special human foods and animal feeds. Moreover, algae can generate a wide range of biofuels, including biohydrogen, methane, oils (triglycerides and hydrocarbons, convertible to biodiesel, jet fuels, etc.), and, to a lesser extent, bioethanol. Meanwhile, this products' production involves different processes such as biochemical and thermochemical conversions or chemical separation or a direct combustion (Huesemann et al. 2010). Like a refinery, it is still possible to obtain other non-energy products in the cultivation of microalgae, such as cosmetics, animal feed, and nutraceuticals. 
Subhadra and Edwards (2011) analyzed algal biorefinery-based integrated industrial sector that produces primary biofuel (biodiesel), coproducts (algal meal-AM), and omega-3 fatty acids (O3FA and glycerin). They demonstrated that biorefineries have a clear market for AM and O3FA up to a certain level; thereafter, diversification for other coproducts is desirable. However, coproduct market analysis and water footprint (WFP) of algal biorefineries need to be studied before large-scale deployment and adoption. In addition, Benemann (2012) argued that saying that "animal feeds could be readily coproduced with algae biofuels are incorrect"; because there are significant differences in the processes focus, quantities production, volume and market values, comparing coproducts with biofuels. However, algal biofuel can be integrated with aquaculture to treat the wastes.

\subsection{Human and Animal uses}

The commercial potential for microalgae represents a largely untapped resource, once there is a huge number of algae species. Some microalgae are mainly used to human nutrition, but are suitable for preparation of animal feed supplements. Like a biorefinary, it is possible to produce from biofuel and coproducts (especially glycerin) to pigments and nutraceuticals.

The production of microalgae started in the early 1960s with the culture of Chlorella as a food additive and had expanded in others countries (Japan, USA, India, Israel, and Australia) until 1980s (Brennan and Owende 2010). The oil (triglycerides) extract from microalgae Chlorella, produced by dark fermentation, has high nutrient value and protein content, and their omega-3 fatty acid—DHA has been used as an ingredient in infant formulas (Brennan Owende 2010; Benemann 2012). D. salina is exploited for its beta-carotene content. Many strains of cyanobacteria (e.g., Spirulina) have been studied to "produce the neurotoxin b-N-methylaminoL-alanine (BMAA) that is linked to amyoptrophic lateral sclerosis-parkinsonism dementia complex, Lou Gehrig's disease (ALS), and Alzheimer's disease" (Brennan and Owende 2010, p. 572). The human consumption of microalgae biomass is restricted to very few species (Chlorella, Spirulina, and Dunaliella species dominate the market) due to the strict food safety regulations, commercial factors, market demand, and specific preparation. According to Subhadra and Edwards (2011),

\footnotetext{
a market survey of global algal producers indicated that more companies are planning to grow algae and extract the O3FA to market to consumers $[\ldots]$ an immediate market of 0.2-0.4 million ton can be foreseen for algal based O3FA. A small portion can be further refined for marketing as human nutraceuticals and a significant portion for fortifying the AM produced as a co-product by algal biofuel refineries.
}

In the end of biodiesel production, it is possible to obtain a significant amount of glycerin that "there is a clear existing market from many industries such as paint and pharmaceuticals." Some studies "have also shown that glycerin in turn can be effectively utilized to grow more algal biomass, another viable method of using glycerin in algal biofuel industry" (Subhadra and Edwards 2011). 
Although the microalgae biomass is being produced essentially to human nutritional products, perhaps it is most attractive as animal feeds (Benemann 2012). Algae are the natural food source of aquaculture species such as mollusks, shrimps, and fish. In addition, it assists the stabilization, improvement, and enhancement of the immune systems of this cultures (Brennan and Owende 2010). They possess high protein rate (typical $50 \%)$, high energy content $(\sim 20 \mathrm{MJ} / \mathrm{kg}$ ), high concentrations of astaxanthin (used in salmon feed), and valuable carotenoids (e.g., lutein-used in chicken feed). Microalgae have also a long chain of omega-3 fatty acids to replace fish meal/oil (Benemann 2012).

\title{
2.6 Energetic Coproducts
}

As stated before, like a refinery, it is still possible to obtain other products in the cultivation of microalgae, such as methane, biohydrogen, and ethanol. Some examples of these possibilities are presented as follows.

Methane. Since early studies on microalgae biofuels, the production of methane biogas by anaerobic digestion of biomass was a main focus (Benemann 2012). This microbial conversion (of organic matter into biogas) produces a mixture of methane, $\mathrm{CO}_{2}$, water vapor, small amounts hydrogen sulfide, and sometimes hydrogen (Gunaseelan 1997 in Huesemann et. al. 2010). This process has been successfully and economically viable despite the recalcitrance of some algal species to biodegradation and inhibition of the conversion process by ammonia released from the biomass. (Benemann 2012; Huesemann et al. 2010). For Huesemann et al. (2010),

\begin{abstract}
Methane generation by anaerobic digestion can be considered to be the default energy conversion process for microalgal biomass, including algal biomass produced during wastewater treatment and for the conversion of residuals remaining after oil extraction or fermentation to produce more valuable liquid fuels.
\end{abstract}

Hydrogen. There are three main processes to produce hydrogen from microalgae: dark fermentation; photo-fermentation, and biophotolysis. The first involves anaerobic conversion of reduced substrates from algae, such as starch, glycogen, or glycerol into hydrogen, solvents, and mixed acids. The second, these organic acids "can be converted into hydrogen using nitrogen-fixing photosynthetic bacteria in a process called photofermentation." The latter, a biophotolysis process uses microalgae to catalyze the conversion of solar energy and water into hydrogen fuel, with oxygen as a byproduct (Huesemann et al. 2010). Although these mechanisms were successfully proven in laboratory scale, they have not yet been developed as a practical commercial process to produce hydrogen from algae (Huesemann et al. 2010; Ferreira et al. 2013).

Ethanol. On the other hand, ethanol can be generated from two alternative processes: storage carbohydrates (fermented with yeast) and endogenous algal enzymes (Benemann 2012; Huesemann et al. 2010). The main process is "yeast fermentation of carbohydrate storage products, such as starch in green algae, glycogen 
in cyanobacteria, or even glycerol accumulated at high salinities by Dunaliella." A self-fermentation by endogenous algal enzymes induced in the absence of oxygen has been reported for Chlamydomonas. Against the very low ethanol yield from both fermentation, several private companies are now reported to be developing ethanol fermentations.

Electricity and Gasification. The microalgae biomass can be dried and combusted to generate electricity, but the drying process is fairly expensive even if solar drying is employed. The combustion and thermal process can destroy the nitrogen fertilizer content of the biomass and generate elevated emissions of NOx. In addition, the combustion process competes with coal and wood biomass that are cheaper than microalgae biomass (Huesemann et al. 2010). Although expensive, this can be a key factor for algae to achieve energetic balance and improve its sustainability. A lot of research is being carried in new and more effective drying techniques in order to reduce costs.

Oil. The significant quantities of neutral lipids, primarily as triacylglycerols, can be extracted from the biomass (green algae and diatoms) and converted into biodiesel or green diesel as substitutes for petroleum-derived transportation fuels. "Lipid biosynthesis is typically triggered under conditions when cellular growth is limited, such as by a nutrient deficiency, but metabolic energy supply via photosynthesis is not" (Roessler 1990 in Huesemann et al. 2010). Further information on algae biodiesel is presented in the next chapter.

Wastewater Treatment. The nutrients for the cultivation of microalgae can be obtained from liquid-effluent wastewater (sewer); therefore, besides providing its growth environment, there is the potential possibility of waste effluents treatment (Cantrell et al. 2008). This could be explored by microalgae farms as a source of income in a way that they could provide the treatment of public wastewater and obtain the nutrients the algae need.

In particular, algae has a potential for recycling nutrients recovered from the wastewater (removing $\mathrm{N}$ and $\mathrm{P}$ ), achieving higher level of treatment and generating biomass. Compared to the conventional water treatment, these processes reduce overall greenhouse gas emissions, burning of digester gas derived from anaerobic digestion.

Biomitigation of $\mathrm{CO}_{2}$ emissions. In the majority of microalgae cultivation, carbon dioxide must be fed constantly during daylight hours. Algae biofuel production can potentially use $\mathrm{CO}_{2}$ in the majority of microalgae cultivation as carbon dioxide must be fed constantly during daylight hours. Algae facilities can potentially use some of the carbon dioxide that is released in power plants by burning fossil fuels. This $\mathrm{CO}_{2}$ is often available at little or no cost (Chisti 2007). Thus, the fixation of the waste $\mathrm{CO}_{2}$ of other sorts of business could represent another source of income to the algae industry. This sort of fixation is already being made in some large algae companies in a trial basis though there is a lack of public data of the results yet. Although this is a very promising future possibility, and some species have proven capable of using the flue gas as nutrients, there are few species that survive at high concentrations of NOx and SOx present in these gases (Brown 1996). Public policies could also perform a great boost in this area 
depending on future $\mathrm{CO}_{2}$ cap and trade emissions or sustainability standards as shown in Chap. "Governance of Biodiesel Production Chain: An Analysis of Palm Oil Social Arrangements".

\section{Algae Biofuels}

After the process of extracting the oil from algae, the resulting product can be converted to biodiesel. The biodiesel produced from algal oil has physical and chemical properties similar to diesel from petroleum, to biodiesel produced from crops of first generation and compares favorably with the International Biodiesel Standard for Vehicles (EN14214) (Brennan and Owende 2010).

Contrasting to other sources of feedstock to produce biofuels, algae-based biofuels present several advantages. These advantages comprise:

1. Capability of producing oil during all year long; therefore, the oil productivity of microalgae is greater compared to the most efficient crops;

2. Producing in blackish water and on not arable land (Searchinger et al. 2008); not affecting food supply or the use of soil for other purposes (Chisti 2007);

3. Possessing a fast-growing potential and several species has $20-50 \%$ of oil content by weight of dry biomass (Chisti 2007);

4. Regarding air quality, production of microalgae biomass can fix carbon dioxide (1 kg of algal biomass fixes roughly $183 \mathrm{~kg}$ of $\mathrm{CO}_{2}$ ) (Chisti 2007);

5. Nutrients for its cultivation (mainly nitrogen and phosphorous) can be obtained from sewage; therefore, there is a possibility to assist the municipal wastewater treatment (Cantrell et al. 2008);

6. Growing algae do not require the use of herbicides or pesticides (Rodolfi et al. 2008);

7. Algae can also produce valuable coproducts, such as proteins and biomass; after oil extraction, the coproducts can be used as animal feed, medicines, or fertilizers (Spolaore et al. 2006; Brennan and Owende 2010), or fermented to produce ethanol or methane (Hirano et al. 1997);

8. Biochemical composition of algal biomass can be modulated by different growth conditions, so the oil yield can be significantly improved (Qin 2005); and

9. Capability of performing the photobiological production of "biohydrogen" (Ghirardi et al. 2000; Ferreira et al. 2013).

The above combination of the potential for biofuel production, $\mathrm{CO}_{2}$ fixation, wastewater treatment, and the possibility of production of biohydrogen highlights the potential applications of the microalgae cultivation.

Compared to other biofuel technologies, the most favorable factors for the cultivation of microalgae for the production of biofuels are they can be grown in brackish (salt) water, on non-fertile land, and the oil yield production is far superior. 


\subsection{Claims against Algae-based Biofuels}

Despite its vocation as a potential source of biofuels, many challenges have hindered the development of biofuels technology from microalgae to become commercially viable.

Among them, and based on recent literature, we elect as the most important:

1. The selection of species must balance the requirements for biofuel production and extraction of valuable by-products (Ono and Cuello 2006);

2. Achieving greater photosynthetic efficiency through the continuous development of production systems (Pulz and Scheibenbogen 1998);

3. Developing techniques for growing a single species, reducing evaporation losses, and diffusion of $\mathrm{CO}_{2}$ (Ugwu et al. 2008);

4. Few commercial cultivating "farms," so there is a lack of data on large-scale cultivation (Pulz 2001);

5. Impossibility of introducing flue gas at high concentrations, due to the presence of toxic compounds such as NOx and SOx (Brown 1996);

6. Choosing algae strains that require freshwater to grow can be unsustainable for operations on a large-scale and exacerbate freshwater scarcity (Mcgraw 2009);

7. Current harvest and dewatering are still too energy intensive (Chen et al. 2009);

8. Some recent life cycle analyses (LCAs) project algae biofuels as having poor energy or greenhouse gas benefits (Benemann 2012; Clarens et al. 2010);

9. Depending on the processes, PBR systems can consume more energy than they produce (Slade and Bauen 2013);

10. Another disappointment that will likely arise is the scarcity of sites with favorable climate, land, water, and $\mathrm{CO}_{2}$ resources, all required in one place (Benemann 2012; Clarens et al. 2010; Slade and Bauen 2013);

11. $\mathrm{CO}_{2}$ supply is relatively expensive, due to high capital and operational costs for piping $\mathrm{CO}_{2}$ to, and transferring it into, the ponds (Benemann 2012).

12. Large-scale cultivation of algal biomass will require a lot of nitrogen and phosphorus; at a small-scale, recycling nutrients from wastewater could potentially provide some of the nutrients required (Slade and Bauen 2013).

Finally, to reach positive energy balance, it will be needed technological advances and highly optimized production systems. The amount of GHG decreases when the microalgae yield increases, primarily because $\mathrm{CO}_{2}$ is the main raw material utilized in photosynthesis during the growth of microalgae. Therefore, it is important to achieve high yields of biomass and oil in the cultivation plant. The mitigation of environmental impacts, and in particular water management, presents both challenges and opportunities, many of which can only be resolved at the local level. Existing cost estimates need to be improved, and this will require empirical data on the performance of systems designed specifically to produce biofuels (Slade and Bauen 2013). 


\section{The Future of Algae Biofuels}

As of today, it has been shown that it is scientifically and technically possible to derive the desired energy products from algae in the laboratory. The question lies, however, in whether it is a technology that merits the support and development to overcome existing scalability challenges and make it economically feasible (Mcgraw 2009). Additionally, the basic economic motivation for biofuels is that they are a convenient, low-priced, domestically producible, and a substitute for oil; an energy source that is getting costlier; and it is mostly imported from politically volatile regions (Castanheira and Silva 2010). Economic feasibility is believed to be currently the main hurdle to overcome for this technology. Current costs associated to both the state of the science and technologies are sizeable and represent a main factor hampering development.

High costs often prevent the market diffusion of novel and efficient energy technologies. As microalgae biofuel is not a mature technology, it becomes important to provide a revision of technological innovation and diffusion aspects to enlighten some available options that may help overpass the barriers found by innovative technologies (Ribeiro and Silva 2013).

It is widely recognized that modern economic analysis of technological innovation originates fundamentally from the work of Schumpeter (1934), who stressed the existence of three necessary conditions for the successful deployment of a new technology: invention, innovation, and diffusion. His seminal work has been constantly referred (Söderholm and Klaassen 2007), and each of the keywords represents different aspects; in particular, invention includes the conception of new ideas; innovation involves the development of new ideas into marketable products and processes; and diffusion, in which the new products and processes spread across the potential market.

Emergent technologies are relatively expensive at the point of market introduction but eventually become cheaper due to mechanisms such as learning-bydoing, technological innovation and/or optimization, and economies of scale. The combined effects of these mechanisms are commonly referred to as technological learning. Over the last decades, learning theories in combination with evolutionary economics have led to the innovation systems theory that expands the analysis of technological innovation, covering the entire innovation system in which a technology is embedded. In particular, "an innovation system is thereby defined as the network of institutions and actors that directly affect rate and direction of technological change in society" (Junginger et al. 2008).

In the emerging energy technologies field, there is a strong need to influence both the speed and the direction of the innovation and technological change. With that in mind, policy makers are putting their efforts on lowering the costs of renewable energy sources to support the development of renewable technologies, either through direct means such as government-sponsored research and development (R\&D), or by enacting policies that support the production of renewable technologies. It is well documented (Johnstone et al. 2010; Popp 2002) that both higher-energy prices and changes in energy policies increase inventive activity on renewable energy technologies (Popp et al. 2011). 
As noted by Popp et al. (2011), the higher costs of renewable energy technologies suggest that policy intervention is necessary to encourage investment. Otherwise, in the lack of public policy favoring the development of renewable energy, production costs remain too high and they do not represent an option in replacing fossil fuels.

Policies to foster innovation should not only focus on the creation and supply of new technologies and innovations, but also on the diffusion and take-up of green innovations in the market place. Such policies need to be well designed to ensure that they support, do not distort the market formation, and should be aligned with competition policies and international commitments (OECD 2011).

With this purpose, several government policies have been introduced in the energy markets worldwide in an effort to reduce costs and accelerate the market penetration of renewables. Although the effectiveness of alternative policies to encourage innovation still needs to be tested empirically, it is expected that these policies will stimulate innovation in renewable energy (US DOE 2010).

In the next section, some of the policies that could enhance the development of microalgae biofuels are, therefore, revised.

\subsection{Recent Investments and Policies}

Impressive biofuel support policies have in recent times been adopted in both the USA (with projected production of 60 billion liters of second-generation biofuel by 2022) and the European Union (with $10 \%$ renewable energy in the transport sector by 2020). Due to the magnitude of the two markets and their sizeable biofuel imports, the US and EU mandates could become an important driver for the global development of advanced biofuels, since current scenarios from the International Energy Agency (IEA) evidence a shortfall in domestic production in both the US and EU that would need to be met with imports (US DOE 2010; EU 2010).

Although algae biofuels are not yet fully competitive in the biofuel market, many venture capital firms had made recent investments in algae fuel ventures (Oligae 2010). Accordingly, a set of policies to assist the development of microalgae technology is being created and constantly improved. These policy incentives aim at increasing renewable energy deployment, in latu sensu, and subsequently will promote development in the algae industry.

In this context, the US Department of Energy published on May 2010 important information for the US policy trends in the "National Algal Biofuels Technology Roadmap" (US DOE 2010). This document represents the output of the National Algal Biofuels Workshop held in Maryland in 2008 and was intended to provide a comprehensive road map report that summarizes the state of algae biofuels technology and documents the techno-economic challenges that have to be met and taken into account before algal biofuel can be produced commercially.

Afterward, the US Environmental Protection Agency (U.S. EPA) suggested revisions to the National Renewable Fuel Standard program (RFS). The proposed changes intended to address changes to the RFS program as required by the Energy Independence and Security Act of 2007 (EISA). The revised statutory requirements 
establish new specific volume standards for cellulosic biofuel, biomass-based diesel, advanced biofuel, and total renewable fuel that must be used in transportation fuel each year. The regulatory requirements for RFS will apply to domestic and foreign producers, and importers of renewable fuel (US EPA 2013).

While cellulosic ethanol is expected to play a large role in meeting the 2007 American Energy Independence and Security Act (EISA) goals, a number of next-generation biofuels show significant promise in helping to achieve the 21 billion gallon goal. Of these candidates, biofuels derived from algae, particularly microalgae, have the potential to help the US meet the new renewable fuels standard (RFS) while at the same time moving the nation ever closer to energy independence (US DOE 2010).

To accelerate the deployment of biofuels produced from algae, the American President Obama and the US Secretary of Energy Steven Chu announced on May 5, 2009, the investment of US $\$ 800$ Millions on new research on biofuels in the American Recovery and Renewal Act (ARRA). This announcement included funds for the Department of Energy Biomass Program to invest in the research, development, and deployment of commercial algal biofuel processes (US EPA 2013). The funding will focus on algal biofuels research and development to make it competitive with traditional fossil fuels as well as the creation of a smooth transition to advanced biofuels that use current infrastructure.

Meanwhile, in order to promote the use of energy from renewable sources, the European Parliament published on April 2009, the Directive 2009/28/EC, which establishes a common framework for the promotion of energy from renewable sources, as well as it establishes sustainability criteria for biofuels and bioliquids (EU 2009).

By the end of 2010, a communication from the European Parliament has set the strategy for a competitive, sustainable, and secure energy future by 2020 . The strategic energy technology (SET) plan sets out a medium-term strategy valid across all sectors. Yet, development and demonstration projects for the main technologies (e.g., second generation biofuels) must be speeded up (EU 2010). The European SET plan lists several energy technologies, which will be required to bring together economic growth and a vision of a decarbonized society. It states that advanced biofuels, namely microalgae, are supposed to play a significant role. EU energy policy aims to represent a green "new deal," which will hopefully enhance the competitiveness of EU industry in an increasingly carbon-constrained world. However, in our dataset, it was possible to include only three European studies. In the forthcoming years, it is expected a rise in the volume of European available data, due to both the strong European transport energy policy drivers and scenarios made available by the IEA regarding Energy Technologies Perspectives 2010. In this sense, incentives and targets are to be met as well as the witnessing of a higher proliferation of pilot-stage algae installations in this highly oil-dependent continent.

\subsection{Expectations Toward Algae-based Biofuels}

Although several challenges remain in the trail toward algae biofuels commercialization and its adoption as a biofuel, as seen so far, an increasing number of companies and 
policy makers seem to believe the rewards outweigh the risks. Thus, the expectation pathway for algae-based biofuels remains uncertain.

Theoretically, microalgae have been shown to be a potential source to produce biodiesel because of their many advantages as a sustainable feedstock for biodiesel production compared to other feedstocks (Ahmad et al. 2011). Nevertheless, not only more innovations are still needed for the development of technologies that reduce costs while increasing the yields of production (Singh and $\mathrm{Gu} 2010$ ), but it is also required a comprehensive set of policies to assist the development of microalgae technology.

In the management area, it is extremely important in the early phases of this promising industry, to deliberate new business models that look at the bioenergy potential of algae through the transportation fuels market, as well as production of other higher-value products so as to make the economics practicable (Singh and Gu 2010).

\section{Conclusion}

The continued use of fossil fuels for energetic purposes is gradually becoming clearer to the society that is unsustainable. Innovative technologies and sources of energy must be developed to replace fossil fuels. In this context, biofuels play a vital role in meeting the energy needs of human beings. There is reason to believe they will continue to do so in the future albeit in a different manner. The basic economic motivation for biofuels is that they are a convenient, low-priced, domestically producible and a substitute for oil. However, alternative sources of biofuel derived from terrestrial crops such as sugarcane, soybeans, maize, and rapeseed inflict a lot of pressure on the global food markets, contribute to water scarcity, and precipitate the destruction of forests. Besides that, many countries cannot grow most of the terrestrial crops due to climate factors or lack of fertile cultivation areas for energetic purposes. In this context, algal biofuels can really make a contribution for the future world sustainability.

In the presented chapter, it is clear that algae are now being intensively researched as a potential biofuel feedstock. In addition to their potentially high yields per unit land area, algae can grow in unsuitable land for agriculture, including industrial areas. Thus, their exploitation offers the possibility of a feedstock for producing biofuel that avoids damage to ecosystems and competition with agriculture associated with other biomass resources. Although many testing and start-up companies are in operation in several countries, cost information is scarce. Along the aforementioned literature review, a consensus was found that biofuels from algae are, in any case, still at the research and development stage and face numerous obstacles related to energy and water needs, and productivity.

Consequently, we revisited the recent developments in biofuel algae-based markets and their technical issues, political standpoints, and environmental impacts. From a research and technology perspective, we stressed the importance of the US bioenergy policies and the European SET plan, as well as by the scenarios from IAE in 2010. These policies inform that several countries have introduced 
mandates and targets for biofuel expansion and, moreover, that production, international trade, and investment have increased sharply in the last few years.

The introduction of these new policies is essential for lowering the costs of algae biofuels, encourage investment, and develop greater diffusion of this emergent technology. Otherwise, in the lack of public policy, currently production costs will eventually remain too high to replace fossil fuels. In the same manner, it is expected that these policies will stimulate innovation to tackle some of the problems in this emerging market.

The problems concerning large-scale production of biodiesel from algal farms on nonarable land include inconsistent and insufficient algal productivities, uncertain capital and operating costs, volatile market prices, and unknown levels of government support. Our survey permits to conclude that although intensive work is being done on many technological issues, economic studies and respective data are scattered, incomplete, and divergent.

With the onset of new policies, incentives, and massive investment in the private and public spheres, more researchers are forging new understanding in the science required to make algal biofuels economically feasible. In the present situation, however, the technology to efficiently produce biodiesel from microalgae is not yet competitive. However, with policy support and incentives, we believe that the algal biofuel industry will continue to develop and assuming that this technology follows renewable energy cost trends, costs will decrease to eventual economic viability. In parallel, processes must be developed to reduce costs and increase production. In this respect, the currently fast rate of development of algae biofuel technology and the actual rising of petroleum-based fuels prices are encouraging algae-based biofuels feasibility in the next few years.

Nevertheless, as shown in this chapter, we are witnessing a rise of companies' strategies of entering new markets. Reports and news of new activities of algaebased companies are frequently on the news nowadays. These are signs that the uncertainties around the commercialization of this still not mature technology are not sufficient to hinder investment decisions.

Acknowledgments Lauro André Ribeiro and Patrícia Pereira da Silva would like to acknowledge that this work has been partially supported by FCT under project grant PEst-C/EEI/ UI0308/2011 and from the Brazilian National Council for the Improvement of Higher Education (CAPES). This paper has been framed under the Energy for Sustainability Initiative of the University of Coimbra and supported by the R\&D Project EMSURE Energy and Mobility for Sustainable Regions (CENTRO 070224 FEDER 002004).

\section{References}

Ahmad AL, Yasin NHM, Derek CJC, Lim JK (2011) Microalgae as a sustainable energy source for biodiesel production: a review. Renew Sustain Energ Rev 15(1):584-593. doi:10.1016/j.rser.2010.09.018

Benemann JR (2012) Microalgae biofuels and animal feeds: an introduction, pp 1-14

Brennan L, Owende P (2010) Biofuels from microalgae-a review of technologies for production, processing, and extractions of biofuels and co-products. Renew Sustain Energ Rev 14(2):557-577 
Brown LM (1996) Uptake of carbon dioxide from flue gas by microalgae. Energ Convers Manage 37(6): 1363-1367

Buford M, DuPont A, Widman N, Ferrell J, Miller M, Bastian H, Steiner J, Lowenfish M, Wight B (2012) Bioenergy feedstock best management practices: summary and research needs. Biomass Research and Development Board. http://www.biomassboard.gov/pdfs/bioenergy_f eedstocks_bmps.pdf. Accessed 30 May 2014

Cantrell KB, Ducey T, Ro KS, Hunt PG (2008) Livestock waste-to-bioenergy generation opportunities. Bioresour Technol 99(17):7941-7953

Castanheira E, Silva PP (2010) Governance of the emerging biofuel markets in European Union: the Portuguese context. Glob Bus Econ Rev 12:230-251

Chen P, Min M, Chen Y, Wang L, Li Y, Chen Q, Yiqin W, et al (2009) Review of the biological and engineering aspects of algae to fuels approach. Int J Agri Bio Eng 2(4). doi:10.3965/ j.issn.1934-6344.2009.04.001-030

Chisti Y (2007) Biodiesel from Microalgae. Biotechnol Adv 25:294-306

Clarens AF, Resurreccion EP, White MA, Colosi LM (2010) Environmental life cycle comparison of algae to other bioenergy feedstocks. Environ Sci Technol 44(5):1813-1819

EC (2012) Com 2012/0288, Proposal for a Directive of the European Parliament and of the Council, amending Directive 98/70/EC relating to the quality of petrol and diesel fuels and amending Directive 2009/28/EC on the promotion of the use of energy from renewable sources

EU 2010 Communication from the Commission to the European Parliament The Council, the European Economic and Social Committee and the Committee of the Regions of December 10th, 2010, energy 2020: a strategy for competitive, sustainable and secure energy, Council of the European Union, Brussels

EU 2009 Directive 2009/28/EC of the European Parliament and of the Council of April 23rd, 2009 on the promotion of the use of energy from renewable sources and amending and subsequently repealing Directives 2001/77/EC and 2003/30/EC, Council of the European Union, Brussels

Ferreira AF, Ribeiro LA, Batista AP, Marques PASS, Nobre BP, Palavra AMF, Silva PPV, Gouveia L, Silva CA (2013) Biorefinery from Nannochloropsis sp. microalga—energy and $\mathrm{CO}_{2}$ emission and economic analyses. Bioresour Tecnol 138:235-244

Ghirardi ML, Zhang L, Lee JW, Flynn T, Seibert M, Greenbaum E, Melis A (2000) Microalgae: a green source of renewable $\mathrm{H}_{2}$. Trends Biotechnol 18(12):506-511

Groom MJ, Gray EM, Townsend PA (2008) Biofuels and biodiversity: principles for creating better policies for biofuel production. Conserv Biol 22(3):602-609

Gunaseelan VN (1997) Anaerobic digestion of biomass for methane production: a review. Biomass Bioenergy 13(1-2):83-114

Huesemann M, Roesjadi G, Benemann J, Metting FB (2010) Biofuels from microalgae and seaweeds, biomass to biofuels: strategies for global industries. Wiley, West Sussex

Hirano A, Ueda R, Hirayama S, Ogushi Y (1997) $\mathrm{CO}_{2}$ fixation and ethanol production with microalgal photosynthesis and intracellular anaerobic fermentation. Energ 22(2-3):137-142

Johnstone N, Hascic I, Popp D (2010) Renewable energy policies and technological innovation: evidence based on patent counts. Environ Resource Econ 45:133-155

Junginger HM, Lako P, Lensink S, van Sark WGJHM, Weiss M (2008) Technological learning in the energy sector. ECN, Group Science, Technology and Society, Copernicus Institute, Utrecht University Utrecht, Netherlands

Mendes R, Fernández H, Coelho J, Reis E, Cabral J, Novais J, Palabra A (1995) Supercritical $\mathrm{CO}_{2}$ extraction of carotenoids and other lipids from Chlorella vulgaris. Food Chem 53:99-103

Mcgraw L (2009) The ethics of adoption and development of algae-based biofuels. UNESCO, Bangkok

OECD (2011) Fostering innovation for green growth. OECD green growth studies, OECD Publishing [internet] 1. [cited 3 jun 4]. Available from: http://dx.doi.org/10.1787/9789264119925-en

Oligae Report: Academic Edition (2010) [internet]. [cited 2010 nov 23], Available from: http://www. oligae.com/ 
Ono E, Cuello JL (2006) Feasibility assessment of microalgal carbon dioxide sequestration technology with photobioreactor and solar collector. Biosyst Eng 95(4):597-606

Patil V, Tran K-Q, Giselrød HR (2008) Towards sustainable production of biofuels from microalgae. Int J Mol Sci 9(7):1188-1195. doi:10.3390/ijms9071188

Pienkos PT, Darzins A (2009) The promise and challenges of microalgal-derived biofuels. Biofuels, Bioprod Biorefin 3(4):431-440

Popp D (2002) Induced innovation and energy prices. American Economic Rev 92:160-180

Popp D, Hascic I, Medhi N (2011) Technology and the diffusion of renewable energy. Energ Econ 33:648-662

Pulz O (2001) Photobioreactors: production systems for phototrophic microorganisms. Appl Microbiol Biotechnol 57(3):287-293

Pulz O, Scheibenbogen K (1998) Photobioreactors: design and performance with respect to light energy input. Adv Biochem Eng Biotechnol 38:123-152

Qin J (2005) Bio-hydrocarbons from algae-impacts of temperature, light and salinity on algae growth. Rural Industries Research and Development Corporation, Barton, Australia

Rengel A (2008) Promising technologies for biodiesel production from algae growth systems. In: 8th European IFSA symposium, vol 2. Clermont-Ferrand, pp 6-10

Ribeiro LA, Silva PPV (2013) Surveying techno-economic indicators of microalgae biofuel technologies. Renew Sustain Energ Rev 25:89-96

Rodolfi L, Zittelli GC, Bassi N, Padovani G, Biondi N, Bonini G, Trdici MR (2008) Microalgae for oil: strain selection, induction of lipid synthesis and outdoor mass cultivation in a lowcost photobioreactor. Biotechnol Bioeng 102(1):100-112

Roessler PG (1990) Environmental control of glycerolipid metabolism in microalgae: commercial implications and future research directions. J Phycol 26:393-399

Schumpeter JA (1934) The theory of economic development: an inquiry into profits, capital, credit, interest, and the business cycle. Harvard University Press, Cambridge

Searchinger T, Heimlich R, Houghton RA (2008) Use of U.S. croplands for biofuels increases greenhouse gases through emissions from land-use change. Sci 319(5867):1238-1240

Sheehan J, Dunahay T, Benemann J, Roessler P (1998) A look back at the US department of energy's aquatic species program: biodiesel from algae, NREL/TP-580-24190. National Renewable Energy Laboratory, USA

Singh J, Gu S (2010) Commercialization potential of microalgae for biofuels production. Renew Sustain Energy Rev 14(9):2596-2610

Singh RN, Sharma S (2012) Development of suitable photobioreactor for algae production-a review. Renew Sustain Energy Rev 16:2347-2353

Slade R, Bauen A (2013) Micro-algae cultivation for biofuels: cost, energy balance, environmental impacts and future prospects. Biomass Bioenergy 53:29-38

Söderholm P, Klaassen G (2007) Wind power in Europe: a simultaneous innovation-diffusion model. Environ Resource Econ 36:163-190

Spolaore P, Joannis-Cassan C, Duran E, Isambert A (2006) Commercial applications of microalgae. J Biosci Bioeng 101(2):87-96

Subhadra BG, Edwards M (2011) Coproduct market analysis and water footprint of simulated commercial algal biorefineries. Appl Energy 88:3515-3523

US Department of Energy (DOE) (2010) Office of energy efficiency and renewable energy, biomass program, National Algal Biofuels Technology Roadmap

U.S. Environmental Protection Agency (2013) (US EPA) [internet] [cited mar 15]. Available from: http://www.epa.gov/otaq/fuels/renewablefuels/index.htm

Ugwu CU, Aoyagi H, Uchiyama H (2008) Photobioreactors for mass cultivation of algae. Bioresour Technol 99(10):4021-4028 